\title{
Nucleotide Accumulation Induced in Staphylococcus aureus by Glycine
}

\author{
JACK L. STROMINGER AND CLAIRE H. BIRGE \\ Departments of Pharmacology, Washington University School of Medicine, St. Louis, Missouri, \\ and University of Wisconsin Medical School, Madison, Wisconsin
}

Received for publication 12 November 1964

\begin{abstract}
Strominger, JACK L. (Washington University School of Medicine, St. Louis, Mo.), and Claire H. Brrge. Nucleotide accumulation induced in Staphylococcus aureus by glycine. J. Bacteriol. 89:1124-1127. 1965.-High concentrations of glycine induce accumulation of four uridine nucleotides in Staphylococcus aureus. Investigations of their structure suggest that these compounds are uridine diphosphate (UDP)-acetylmuramic acid, UDP-acetylmuramyl-gly-D-glu-L-lys, UDP-acetylmuramyl-L-ala-D-glu-L-Jys and UDP-acetylmuramyl-gly-D-glu-L-lys-D-ala-D-ala. The mechanism by which glycine may induce uridine nucleotide accumulation and protoplast formation is discussed.
\end{abstract}

The peculiar effects of glycine on bacteria have been known since 1943 (Gordon and Gordon, 1943). High concentrations of glycine induce bacteriolysis or morphological alterations, including L-form transformation, in various bacteria (Maculla and Cowles, 1948; Gordon, Hall, and Stickland, 1949; Dienes and Weinberger, 1951; Dienes and Zamecnik, 1952; Rubio-Huertos and Gonzalez-Vazquez, 1960). These effects are similar to and additive with the effects of penicillin and D-cycloserine (Welsch, 1958; Welsch and Osterrieth, 1958; Michel and Hijmans, 1960). In hypertonic sucrose, spheroplast formation in Escherichia coli occurs, presumably due to some interference with cell-wall synthesis (Welsch, 1958; Welsch and Osterrieth, 1958). Glycine also induces in Staphylococcus aureus accumulation of uridine diphosphate (UDP) acetylamino sugar compounds, presumably precursors of the cell wall (Park, 1958). The accumulated nucleotides were not identified, however. In the present paper, the isolation and studies of the structure of these nucleotides are presented.

\section{Materials and Methods}

The organism employed was $S$. aureus strain Copenhagen. Log-phase cells $(200 \mathrm{ml})$ were suspended in growth medium (Strominger, 1957) containing $0.5 \mathrm{M}$ glycine, incubated at $37 \mathrm{C}$ with vigorous shaking for $90 \mathrm{~min}$, and then harvested again. Measurement of uridine nucleotide accumulation, isolation of accumulated nucleotides by two-dimensional paper chromatography, and analyses of nucleotides were carried out as described in the preceding paper (Wishnow et al., 1965).

\section{RESUlts}

Glycine-induced nucleotide accumulation. The extract of cells harvested from a 1-liter culture treated for $90 \mathrm{~min}$ with $0.5 \mathrm{~m}$ glycine contained $26 \mu$ moles of acetylamino sugar ester, presumably uridine nucleotide (compared with 0.5 to 1 $\mu$ mole/liter in the control culture). The nucleotides in this extract were recovered by charcoal adsorption and elution. The eluates were reduced to a volume of 0.4 to $0.5 \mathrm{ml}$, and brought to about $p \mathrm{H} 4$ with isobutyric acid. When this material was subjected to two-dimensional paper chromatography, a number of ultraviolet-absorbing materials was observed (Fig. 1). [The sharp separation of compounds 1,2 , and 3 was difficult to obtain. Optimal results were obtained when the eluates were neutralized with isobutyric acid, rather than $\mathrm{HCl}$, and when the chromatograms were developed at a low temperature (about $18 \mathrm{C})$. At this temperature, the first dimension required 48 to $72 \mathrm{hr}$ for development.] Compounds 1 to 4 had the typical spectra of a uridine nucleotide in both $0.05 \mathrm{~N} \mathrm{HCl}$ and $0.1 \mathrm{~N} \mathrm{NaOH}$. These compounds were eluted from two chromatograms (similar to that shown in Fig. 1), each representing $200 \mathrm{ml}$ of culture. The eluates of each of the compounds were pooled, subjected again to two-dimensional paper chromatography, eluted, and analyzed. The amounts of these compounds recovered from $400 \mathrm{ml}$ of culture were: compound 1, $0.82 \mu$ mole; compound 2, $0.42 \mu$ mole; compound $3,0.76 \mu$ mole; and compound 4, 1.66 $\mu$ moles. Thus, the recovery $(3.7 \mu$ moles $)$ was about $35 \%$. About one-third of the material was lost in adsorption and elution from charcoal, 
and the other third was lost during the separation.

Analyses of accumulated uridine nucleotides. All four uridine nucleotides contained 2 moles of phosphate and 1 mole of acetylamino sugar per mole of uridine (Table 1). Samples were subjected

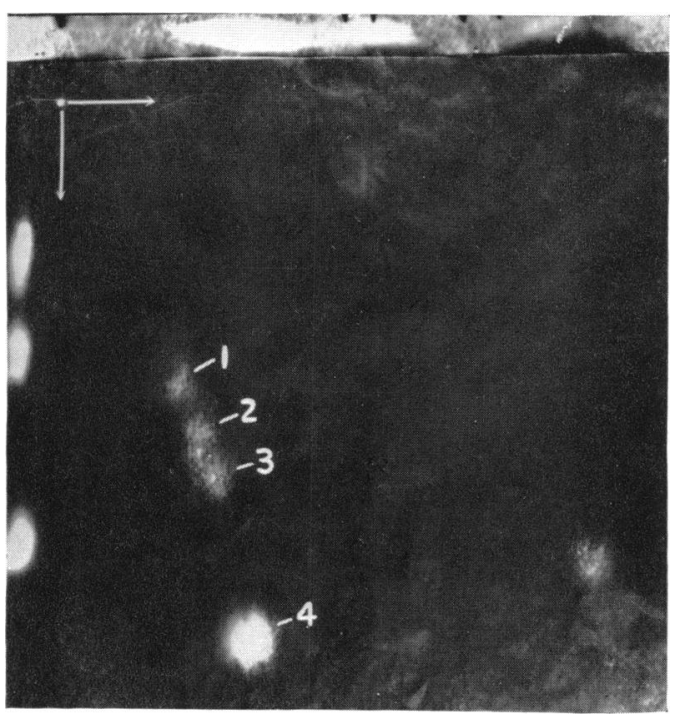

FIG. 1. Nucleotides accumulated in cells treated for 90 min with 0.5 M glycine. The numbers are the same as those used in Table 1. to acid hydrolysis and then analyzed on a Beckman Spinco amino acid analyzer. Compound 4 contained no amino acids. In the hydrolysate of this compound, muramic acid was found, but no glucosamine was present (although UDP-acetylglucosamine has nearly the same position as UDP-acetylmuramic acid in this system). Compounds 1, 2, and 3 also contained muramic acid, and in addition contained amino acids in the following ratios: compound 1: gly-glu-lys, $1: 1: 1$; compound 2: gly-glu-lys-ala, $0.2: 1: 1: 1$; and compound 3: gly-glu-lys-ala, 1:1:1:2. Analyses for D- and L-alanine were carried out. Compound 2 contained mainly L-alanine and compound 3 only D-alanine (Table 1). The amino terminal group in compounds 1,2 , and 3 was found, in each case, to be $\epsilon$-amino-lysine.

\section{Discussion}

The data obtained are compatible with the following structures: compound 1, UDP-acetylmuramyl-gly-D-glu-L-lys; compound 2, UDPacetylmuramyl-L-ala-D-glu-L-lys; compound 3, UDP-acetylmuramyl-gly-D-glu-L-lys-D-ala-D -ala; and compound 4, UDP-acetylmuramic acid. It is assumed that the glutamic acid and lysine have the same configuration as has been found in other nucleotides isolated from this organism, and that the sequences follow the general pattern previously established (see Strominger, 1962). Compound 2 was present in small amounts, and

TABLE 1. Analyses of accumulated uridine nucleotides ${ }^{a}$

\begin{tabular}{|c|c|c|c|c|c|c|c|c|c|c|}
\hline Compound & $\mathrm{PO}_{4}{ }^{b}$ & $\begin{array}{l}\text { Acetyl- } \\
\text { amino } \\
\text { sugar }^{c}\end{array}$ & $\underset{\text { acid }^{d}}{\text { Muramic }}$ & Glycine $^{x}$ & Glucose $e^{d}$ & Lysine ${ }^{d}$ & Alanine $e^{d}$ & D-Alanine $e^{e}$ & L-Alanine $e^{e}$ & $\underset{\text { groups }^{f}}{\text { Free amino }}$ \\
\hline 1 & 1.90 & 1.04 & 0.82 & 0.98 & 1.02 & 0.97 & 0 & - & - & $\begin{array}{c}\epsilon \text {-Amino } \\
\text { lys }\end{array}$ \\
\hline 2 & 1.96 & 0.92 & 0.70 & 0.23 & 0.94 & 1.01 & 0.93 & 0.12 & 0.84 & $\begin{array}{c}\text { 6-Amino } \\
\text { lys }\end{array}$ \\
\hline 3 & 1.90 & 0.91 & 0.78 & 0.94 & 0.94 & 1.03 & 1.95 & 1.90 & 0.03 & $\begin{array}{c}\epsilon \text {-Amino } \\
\text { lys }\end{array}$ \\
\hline 4 & 1.92 & 0.94 & 0.80 & 0 & 0 & 0 & 0 & - & - & - \\
\hline
\end{tabular}

${ }^{a}$ Results are presented as moles per mole of uridine (measured from its 262-m $\mu$ absorbancy by use of $\epsilon=9,890)$.

${ }^{b}$ Measured by the method of Lowry et al. (1951).

$c$ Measured by the modified Morgan-Elson method after mild acid hydrolysis (Ressig, Strominger, and Leloir, 1955; Strominger, 1957).

${ }^{d}$ Measured after acid hydrolysis on the Beckman Spinco amino acid analyzer. The low values for muramic acid are due to some loss of this sugar during the hydrolysis.

- Measured by use of the specificity of D-amino acid oxidase and L-alanine- $\alpha$-ketoglutarate trans aminase (Strominger and Threnn, 1959).

$f$ Measured, after dinitrophenylation and acid hydrolysis, by thin-layer chromatography by use of an unpublished method of D. J. Tipper. 
was overlapped on the chromatograms by compounds 1 and 3 . The analytical data obtained are compatible with the structure indicated for compound 2, if it is assumed that the material analyzed was contaminated by $15 \%$ of compounds 1 and 3 . Further purification would obviously be needed to establish the composition of compound 2 with certainty. Compound 2 is, however, in exactly the same position on the two-dimensional paper chromatogram as UDPacetylmuramyl-L-ala-D-glu-L-lys from D-cycloserine-treated cells (see Fig. 6 of Wishnow et al., 1965). It is also of interest that compound 1 (UDP-acetylmuramyl-gly-D-glu-L-lys) has the same mobilities in the two solvents relative to compound 2, as does compound 3 (UDP-acetylmuramyl-gly-D-glu-L-lys-D-ala-D-ala) relative to UDP-acetylmuramyl-L-ala-D-glu- L-lys - D - ala - Dala from penicillin-treated cells (see Fig. 5 of Wishnow et al., 1965).

Compound 4, UDP-acetylmuramic acid, is the major compound which accumulated. This fact suggests that inhibition of cell-wall synthesis by high concentrations of glycine is probably due to inhibition of the reaction in which L-alanine is added to UDP-acetylmuramic acid (Ito and Strominger, 1962a, b). Although glycine may have other effects on cell-wall synthesis, inhibition of the L-alanine adding enzyme would be a sufficient explanation of its physiological effects in bacteria, i.e., morphological alterations and nucleotide accumulations. Some glycine is apparently incorporated into the uridine nucleotides in place of L-alanine (compounds 1 and 3 ). It is not known whether these glycine-containing nucleotides can be utilized for cell-wall synthesis or whether cell walls containing glycine linked to acetylmuramic acid would be as stable as the normal cell wall.

These observations recall that $\mathrm{D}$-methionine and $\mathrm{D}$-serine, when present in the growth medium at high concentrations, are both incorporated into cell wall, presumably in place of some normal constituent (Lark and Lark, 1961; Whitney and Grula, 1964). Also, hydroxylysine can be incorporated in place of lysine (Tsung et al., 1962). Moreover, a compound isolated from a partial acid hydrolysate of normal cell walls of Micrococcus lysodeikticus contained acetylglucosamine, acetylmuramic acid, and glycine in equimolar amounts, together with a small amount of alanine, glutamic acid, and lysine (Perkins and Rogers, 1959). A linkage of glycine to muramic acid was not established in this compound, owing to the small amount of material which was obtained. No similar material was encountered during studies of the cell wall of S. aureus (Ghuysen and Strominger, $1963 a, b)$.
This study was undertaken in the hope that investigation of the effects of high concentrations of glycine might lead to some information regarding the mechanisms of glycine cross-bridge formation in the cell wall of $S$. aureus. These bridges are built on the $\epsilon$-amino groups of lysine (Mandelstam and Strominger, 1961). It is apparent, however, that no clues relative to cross-bridge formation have been uncovered, because the $\epsilon$-amino groups of lysine are unsubstituted in all of the compounds found. Apparently, glycine found in the isolated nucleotides is substituted for another amino acid, L-alanine.

\section{ACKNOWLEDGMENTS}

This investigation was supported by Public Health Service research grant AI-06247 from the National Institute of Allergy and Infectious Diseases, and by National Science Foundation grant GB-1823.

\section{Literature Cited}

Dienes, L., and H. J. Weinberger. 1951. The $\mathrm{L}$ forms of bacteria. Bacteriol. Rev. 15:245-288. Dienes, L., and P. C. Zamecnik. 1952. Transformation of bacteria into $\mathrm{L}$ forms, by amino acids. J. Bacteriol. 64:770-771.

Ghuysen, J. M., and J. L. Strominger. $1963 a$. Structure of the cell wall of Staphylococcus aureus. I. Preparation of fragments by enzymatic hydrolysis. Biochemistry 2:1110.

Ghuysen, J. H., and J. L. Strominger. $1963 b$. Structure of the cell wall of Staphylococcus aureus. II. Separation and structure of disaccharides. Biochemistry 2:1119.

Gordon, J., R. A. Hall, and L. H. Stickland. 1949. A comparison of the degree of lysis by glycine of normal and glycine resistant organisms. J. Pathol. Bacteriol. 61:581.

Ito, E., ANd J. L. Strominger. 1962a. Enzymatic synthesis of the peptide in bacterial uridine nucleotides. I. Enzymatic addition of L-alanine, D-glutamic acid and L-lysine. J. Biol. Chem. 237:2689.

Ito, E., ANd J. L. Strominger. 1962b. Enzymatic synthesis of the peptide in bacterial uridine nucleotides. II. Enzymatic synthesis and addition of D-alanyl-D-alanine. J. Biol. Chem. 237: 2696.

Lark, C., AND K. G. LaRK. 1961. Studies on the mechanism by which $\mathrm{D}$-amino acids block cell wall synthesis. Biochim. Biophys. Acta 49:308.

Lowry, O. H., N. J. Rosebrough, A. L. Farr, AND R. J. RANDALl. 1951. Protein measurement with the Folin phenol reagent. J. Biol. Chem. 193:265-275.

Maculla, E. S., And P. B. Cowles. 1948. The use of glycine in the disruption of bacterial cells. Science 107:376.

Mandelstam, M. H., and J. L. Strominger. 1961. On the structure of the cell wall of Staphylococ- 
cus aureus. Biochem. Biophys. Res. Commun. 5:466.

Michel, M. F., and W. Hijmans. 1960. The additive effect of glycine and other amino acids on the induction of the L-phase group $\mathrm{A} \alpha$-haemolytic streptococci by penicillin and $\mathrm{D}$-cycloserines J. Gen. Microbiol. 23:35.

PARK, J. T. 1958. Inhibition of cell wall synthesis in Staphylococcus aureus by chemicals which cause accumulation of wall precursors. Biochem. J. 70:2P.

Perkins, H. R., and H. J. Rogers. 1959. The products of partial acid hydrolysis of mucopeptide from cell walls of Micrococcus lysodeikticus. Biochem. J. 72:647.

Ressig, J. L., J. L. Strominger, and L. Leloir. 1955. A modified colorimetric method for the estimation of $N$-acetylamino sugars. J. Biol. Chem. 217:959.

Rubio-Huertos, M., and C. Gonzalez-VAzQuez. 1960. Morphology and pathogenicity of $L$ forms of Clostridium tetani induced by glycine. Ann. N.Y. Acad. Sci. 79:626.

Strominger, J. L. 1957. Microbial uridine-5'pyrophosphate $N$-acetylamino sugar compounds. I. Biology of the penicillin-induced accumulation. J. Biol. Chem. 224:509.

Strominger, J. L. 1962. Biosynthesis of bacterial cell walls, p. 413. In I. C. Gunsalus and R. Y. Stanier [ed.], The bacteria, vol. 3. Academic Press, Inc., New York.

Strominger, J. L., and R. H. Threnn. 1959. The optical configuration of the alanine residues in a uridine nucleotide and in the cell wall of Staphylococcus aureus. Biochim. Biophys. Acta 33:280.

Tsung, C. M., W. G. Smith, F. R. Leach, And L. M. Henderson. 1962. Hydroxylysine metabolism in Streptococcus faecalis. J. Biol. Chem. 237:1194.

WelsCH, M. 1958. Formation de protoplastes d'Escherichia coli sous l'influence de la glycine et d'autres acides amines. Schweiz. Z. Allgem. Pathol. Bakteriol. 21:741.

Welsch, M., and P. Osterrieth. 1958. A comparative study of the transformation of gramnegative rods into "protoplasts" under the influence of penicillin and glycine. Antonie van Leeuwenhoek J. Microbiol. Serol. 24:257.

Whitney, J. G., ANd E. A. Grula. 1964. Incorporation of D-serine into the cell wall mucopeptide of Micrococcus lysodeikticus. Biochem. Biophys. Res. Commun. 14:375.

Wishnow, R. M., J. L. Strominger, C. H. Birge, AND R. H. Threnn. 1965. Biochemical effects of novobiocin on Staphylococcus aureus. J. Bacteriol. 89:1117-1123. 